\title{
Embalagens vazias de agrotóxicos: avaliação dos fumicultores da Linha João Alves, município de Santa Cruz do Sul, RS
}

Empty pesticide containers: evaluation of the tobacco growers Linha João Alves, city of Santa Cruz do Sul, RS

\section{Leandro Calegari}

Universidade Federal de Campina Grande - UFCG - Patos - Paraíba - Brasil

\section{Diego Martins Stangerlin}

\author{
Universidade Federal de Mato Grosso - UFMT - Cuiabá - Mato Grosso - Brasil
}

\section{Darci Alberto Gatto}

\author{
Universidade Federal de Pelotas - UFPel - Capão do Leão - Rio Grande do Sul - Brasil
}

\section{Carina Cristina Agnes Calegari}

Universidade de Santa Cruz do Sul - Unisc - Santa Cruz do Sul - Rio Grande do Sul - Brasil

\begin{abstract}
Resumo: Embora o tabaco se constitua em uma importante fonte de renda para várias famílias do Vale do Rio Pardo, o uso de agrotóxicos nesta cultura é responsável por muitos problemas ambientais e de saúde pública nesta região. Através de entrevistas realizadas na localidade de Linha João Alves, município de Santa Cruz do Sul, RS, o presente estudo apresentou como objetivos caracterizar os produtores e principais agrotóxicos utilizados por estes, identificar as formas de descarte das embalagens vazias utilizadas na lavoura do tabaco, verificando os possíveis impactos ao meio ambiente e à saúde decorrentes destas práticas. Conforme os dados obtidos, os fumicultores analisados caracterizam-se por serem pequenos produtores rurais, sendo a área média destinada à fumicultura de apenas 3,9 ha. Consideraram indispensável o uso de agrotóxicos na produção, sendo Primeplus $\AA$, Orthene $\AA$, Confidor $\AA$, Gamit $\AA$, Roundup $\AA$, Actara $\AA^{\circledR}$ e Rovral ${ }^{\circledR}$ os principais citados, sendo a maioria deles pouco tóxicos. No entanto, um deles (Gamit) é classificado como altamente tóxico, e outro (Actara) como medianamente tóxico. Apesar de adquirirem o Equipamento de Proteção Individual (EPI), através do pacote tecnológico das empresas fumageiras, a maioria dos entrevistados declarou não utilizá-lo devidamente. Todas as embalagens vazias de agrotóxicos utilizadas na localidade estão sendo recolhidas, conforme exigido pela Lei n. $\stackrel{9}{9.974}$, de 06 de junho de 2000. Desta forma, os impactos negativos provenientes do descarte das embalagens vazias estão sendo minimizados, embora estudos laboratoriais façam-se necessários para uma análise mais minuciosa.
\end{abstract}

Palavras-chave: Tabaco. Agrotóxico. Embalagens vazias. Santa Cruz do Sul. Linha João Alves.

Abstract: Although tobacco has become an important source of income for many families in Vale do Rio Pardo, the use of pesticides in this culture is responsible for many environmental and public health problems in such a region. Through interviews conducted at Linha João Alves district, in the city of Santa Cruz do Sul, RS, this study aimed to characterize the producers and main pesticides used by them; identify ways to get rid of empty containers used in tobacco farming, checking the possible impacts to the environment and to the health considering these practices. According to the obtained data, the analyzed growers are characterized by being small farmers, and the average area for tobacco growing of only 3.9 ha. The use of pesticides in the production was considered necessary, and Primeplus, Orthene, Confidor, Gamit, Roundup, Actara and Rovral were the main ones cited, most of them slightly toxic. However, one of them (Gamit) is classified as highly toxic, and another (Actara) as moderately toxic. In spite of acquiring the Personal Protective Equipment (PPE), through the technology package of tobacco companies, the majority of the interviewees said not to use it properly. All empty containers of pesticides used in the locality are being collected, as required by Law No. 9974, by 06 June 2000 . Thus, the negative impacts from the disposal of empty containers are being minimized, although laboratory studies make it necessary for a more detailed analysis.

Keywords: Tobacco. Pesticides, Empty containers. Santa Cruz do Sul. Linha João Alves. 



\section{Introdução}

$\mathrm{O}$ aumento da população mundial exigiu a necessidade da expansão da produção agrícola. A Revolução Verde, programa com o objetivo de aumentar a produtividade, apesar de ter atingido seu objetivo, proporcionou considerável aumento do uso de agrotóxicos. Apesar de também reduzir os custos da produção, o uso de agrotóxicos trouxe consigo consequências negativas, principalmente quando sua aplicação é realizada indiscriminadamente, podendo gerar envenenamentos de agricultores e do meio ambiente.

Neste contexto da Revolução Verde também está inserida a fumicultura brasileira. O Brasil mantém a liderança mundial nas exportações de fumo em folha desde 1993. A qualidade, a possibilidade de produção com baixos custos (um dos menores dentre os países produtores) e a capacidade de abastecimento do mercado externo são fatores que têm garantido a expansão das exportações brasileiras. Em virtude da redução na produção em alguns países, principalmente Estados Unidos e Zimbábue, que até pouco tempo eram os principais concorrentes das exportações brasileiras, o Brasil vem aumentando sua produção e participação no mercado externo (BONATO, 2006, p.17).

A partir da Segunda Guerra Mundial, com a descoberta do extraordinário poder inseticida do organoclorado dicloro-difenil-tricloroetano (DDT) e dos organofosforados, inicialmente utilizados como armas de guerra, deu-se início à grande disseminação dessas substâncias na agricultura. Nos anos 60 , os agrotóxicos começaram a ser amplamente difundidos como parte fundamental da agricultura moderna, amparando a Revolução Verde brasileira (OLIVEIRA et al., 2003, p.306-307).

Empregada em qualquer cultivo agrícola, o simples abandono das embalagens vazias de agrotóxicos na lavoura, prática muito comum até pouco tempo atrás, colocava as pessoas e 0 meio ambiente a sérios riscos devido a resíduos ainda presentes nas embalagens.
Embora o tabaco constitua-se em uma importante fonte de renda para milhares de famílias de agricultores do Brasil, principalmente na região Sul, existem muitos problemas relacionados com a cultura do fumo, tanto no processo produtivo quanto no consumo do produto, conforme apresentado por Bonato (2006, p. 28-32), descritos abaixo: tabagismo, uso de agrotóxicos, utilização de mão-de-obra infantil e degradação do meio ambiente (poluição e desmatamento).

Embora a pesquisa tenha avançado em relação à redução do uso de agrotóxicos nas lavouras de fumo (e das demais culturas), o destino das embalagens continua sendo um problema ao meio ambiente. Mesmo com a tríplice lavagem das embalagens vazias, os produtos químicos podem continuar concentrados nos recipientes, contaminando a água e o solo.

A utilização de lenha para a secagem do fumo nas estufas também traz consequências ao meio ambiente. Toda queima de árvore gera poluição, os desmatamentos reduzem a biodiversidade $e$, adicionalmente, nem sempre as matas nativas são garantidas pelo reflorestamento (BONATO, 2006).

O Programa de recebimento de embalagens de agrotóxicos tríplice lavada foi implantado no Estado do Rio Grande do Sul em outubro de 2000, por meio de um convênio firmado entre a Associação dos Fumicultores do Brasil (AFUBRA), o Sindicato das Indústrias do Fumo (SINDIFUMO) e o Consórcio Intermunicipal de Recebimentos de Embalagens Vazias de Agrotóxicos (Cinbalagens). A tríplice lavagem tem como objetivo reduzir significativamente os níveis de resíduos internos dos mesmos, cumprindo-se assim o que determina o Artigo 53 do Decreto $n^{\circ}$. 4.074, de 04 de janeiro de 2002, a qual regulamenta a Lei ํㅜ‥802, de 11 de julho de 1989.

Art. 53: Os usuários de agrotóxicos e afins deverão efetuar a devolução das embalagens vazias, e respectivas tampas, aos estabelecimentos comerciais em que foram adquiridos, observadas as instruções constantes dos rótulos e das bulas, no prazo de até um ano, contado da data de sua compra. 
§ 2: É facultada ao usuário a devolução de embalagens vazias a qualquer posto de recebimento ou centro de recolhimento licenciado por órgão ambiental competente e credenciado por estabelecimento comercial. $\S$ 3: : Os usuários deverão manter à disposição dos órgãos fiscalizadores os comprovantes de devolução de embalagens vazias, fornecidas pelos estabelecimentos comerciais, postos de recebimento ou centros de recolhimento, pelo prazo de, no mínimo, um ano, após a devolução da embalagem" ... (Decreto nº. 4.074, de 04 de janeiro de 2002)

Ainda no primeiro ano, o Programa apresentou êxito, coletando aproximadamente 420 mil recipientes de produtos químicos utilizados nas propriedades dos fumicultores, envolvendo todos os 260 municípios do Estado e beneficiando mais de 70 mil produtores (NEUMANN, 2001, p.96).

Conforme apontou Machado (2007), a empresa responsável pela operação conseguiu evitar que 9 mil frascos de agrotóxicos fossem deixados em contato com ambiente nas regiões de Linha João Alves, Cerro Alegre Alto, Malhada, Cerro Alegre Baixo, São José da Reserva e Reserva dos Kroth. A mesma atividade ocorreu em Rio Pardinho, onde dezenas de produtores foram até os locais estabelecidos para realizar a entrega. Os produtores que aderem ao Programa recebem recibos, os quais são fundamentais para apresentação aos órgãos de fiscalização ambiental.

Dados mais recentes apontaram que no ano de 2009 foram destinadas 1.775 toneladas, contra 1.405 toneladas referentes ao ano de 2008, um acréscimo, portanto, de aproximadamente $26 \%$. De acordo com o Instituto Nacional de Processamento de Embalagens Vazias (INPEV), o qual tem como associados os fabricantes de agrotóxicos, somente no mês de agosto, 210 toneladas de embalagens vazias seguiram para um destino final ambientalmente correto (reciclagem ou incineração) no Estado (GAZETA DO SUL, 2009).

Neste sentido, o objetivo geral deste estudo foi investigar o comportamento de produtores rurais da Linha João Alves, município de Santa Cruz do Sul, RS, Brasil, quanto à utilização de agrotóxicos na lavoura de tabaco. Os objetivos específicos foram caracterizar os produtores através de sua idade, escolaridade, tamanho da propriedade, tempo de produção, dentre outras; identificar a origem e os principais agrotóxicos utilizados nas lavouras; identificar as formas de descarte das embalagens e; verificar possíveis impactos ao meio ambiente e a saúde dos agricultores.

\section{Materiais e métodos}

\section{1 Área de Estudo}

O estudo foi realizado no município de Santa Cruz do Sul, situado na Depressão Periférica Sul-riograndense, o qual possui uma área de aproximadamente $733 \mathrm{~km}^{2}$ e população de aproximadamente 116 mil habitantes, dos quais $84 \%$ vivem em área urbana, e 16\% vivem no meio rural, tendo a agricultura como principal fonte de renda, conforme dados do Instituto Brasileiro de Geografia e Estatística (IBGE, 2007).

Dentre os diversos distritos pertencentes ao município de Santa Cruz do Sul destaca-se a Linha João Alves, a qual possui aproximadamente 255 famílias (IBGE, 2007) e situa-se na direção leste da mancha urbana (Figura 1). 
Figura 1. Mapa do Município de Santa Cruz do Sul e localização do Distrito de Linha João Alves, Estado do Rio Grande do Sul, Brasil.
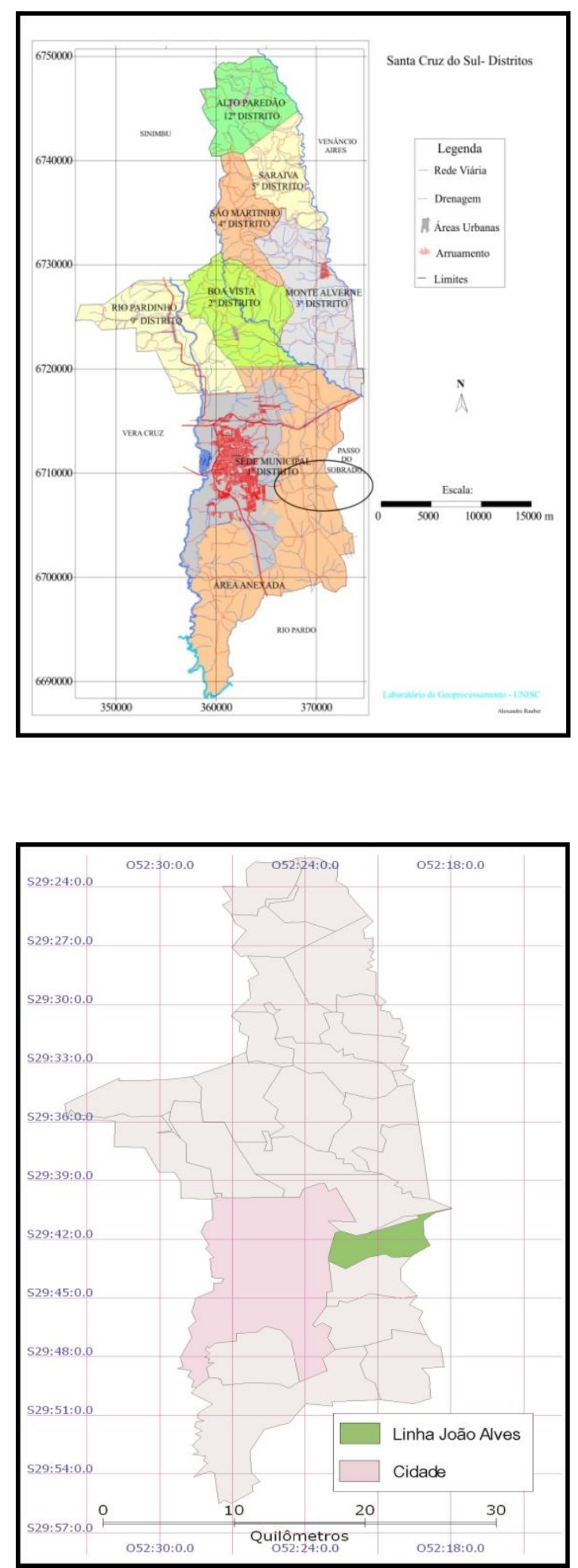

Fonte: Laboratório de Geoprocessamento - UNISC, 2009.

\subsection{Avaliação dos produtores de tabaco (fumicultores)}

A pesquisa foi realizada através de um questionário semi-estruturado aos agricultores produtores de tabaco (fumicultores) no referido distrito (Apêndice 1). As visitas foram feitas nos estabelecimentos rurais das famílias, entre os meses de julho e novembro de 2009. O critério de escolha das famílias para as entrevistas foi aleatório, dependendo de sua disponibilidade no momento da visita, até que um total de 30 famílias fosse consultado.

\section{Resultados e discussão}

Os questionários foram respondidos predominantemente pelos chefes de famílias homens (67\%), sendo o restante dividido entre as mulheres e, em alguns casos, por ambos, sendo que a maior parte deles possuía entre 41 e 60 anos (Figura 2 e Figura 3).

Figura 2. Caracterização dos chefes de família que responderam ao questionário na Linha João Alves, município de Santa Cruz do Sul, RS

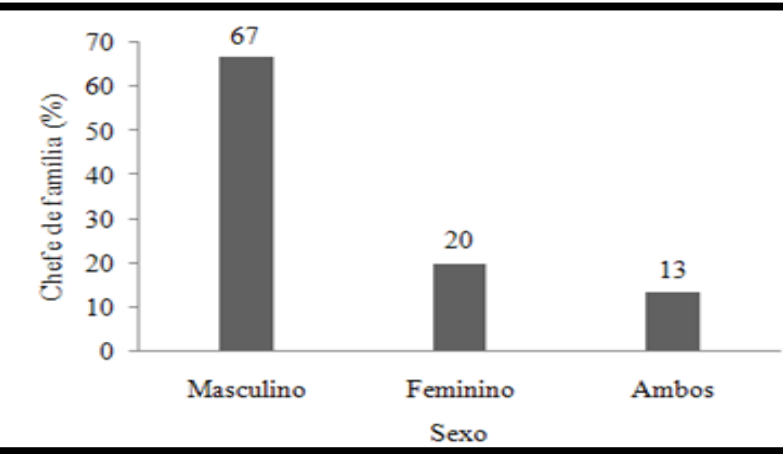

Fonte: Elaborada pela autora a partir das informações recolhidas pelos fumicultores da Linha João Alves, município de Santa Cruz do Sul, RS (2009).

Indivíduos maiores de 60 anos que responderam ao questionário corresponderam à minoria (10\%), e estes, por não mais poderem aplicar agrotóxicos, passam essa tarefa para parentes mais novos (Figura 3). 
Figura 3. Caracterização da faixa etária dos chefes de família que responderam ao questionário na Linha João Alves, município de Santa Cruz do Sul, RS

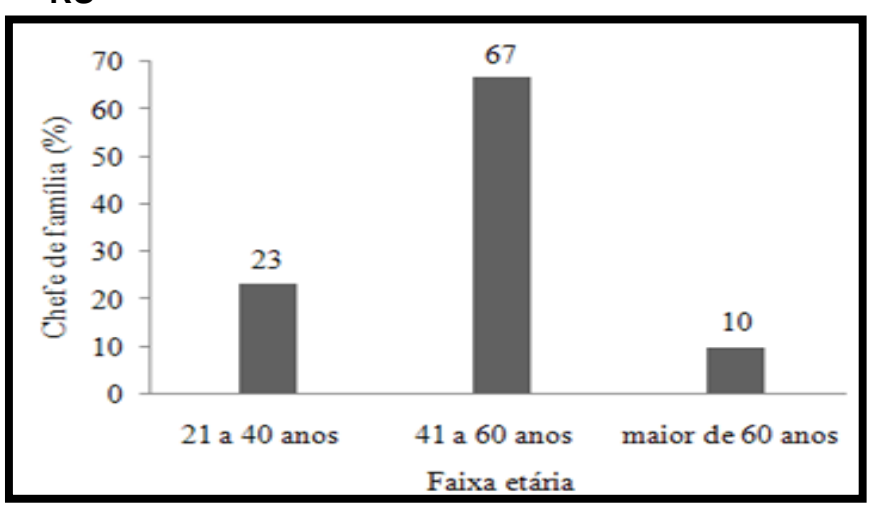

Fonte: Elaborada pela autora a partir das informações recolhidas pelos fumicultores da Linha João Alves, município de Santa Cruz do Sul, RS (2009).

Com relação à escolaridade, o máximo constatado pela entrevista foi 0 do Ensino Fundamental completo, correspondendo à minoria (7\%). A grande maioria (70\%) declarou possuir até a 5o série, portanto, Ensino Fundamental incompleto.

Figura 4. Escolaridade dos chefes de família da Linha João Alves, município de Santa Cruz do Sul, RS

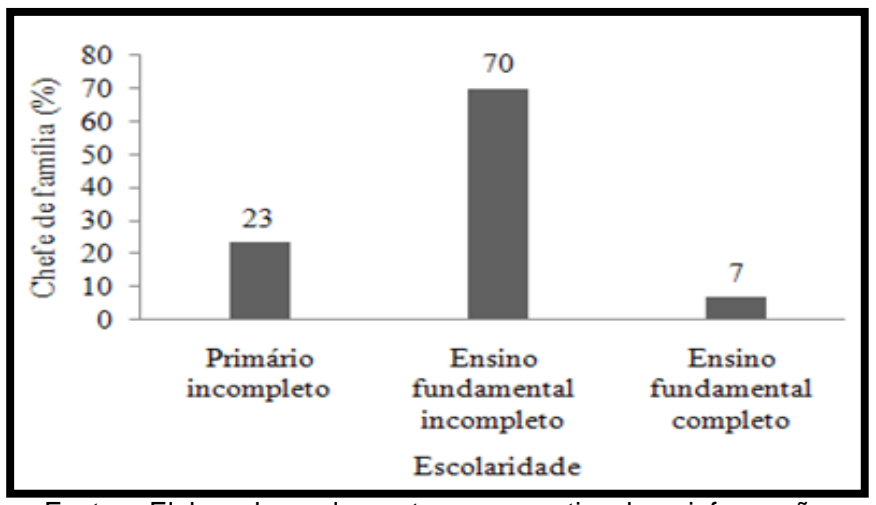

Fonte: Elaborada pela autora a partir das informações recolhidas pelos fumicultores da Linha João Alves, município de Santa Cruz do Sul, RS (2009).

Quanto ao tempo de produção de tabaco na localidade, $43 \%$ dos agricultores produzem entre a 21 e 30 anos, seguido dos que produzem a mais de 31 anos $(30 \%)$, sendo que o restante produz há menos tempo (Figura 5).
Figura 5. Tempo de produção de tabaco da Linha João Alves, município de Santa Cruz do Sul, RS

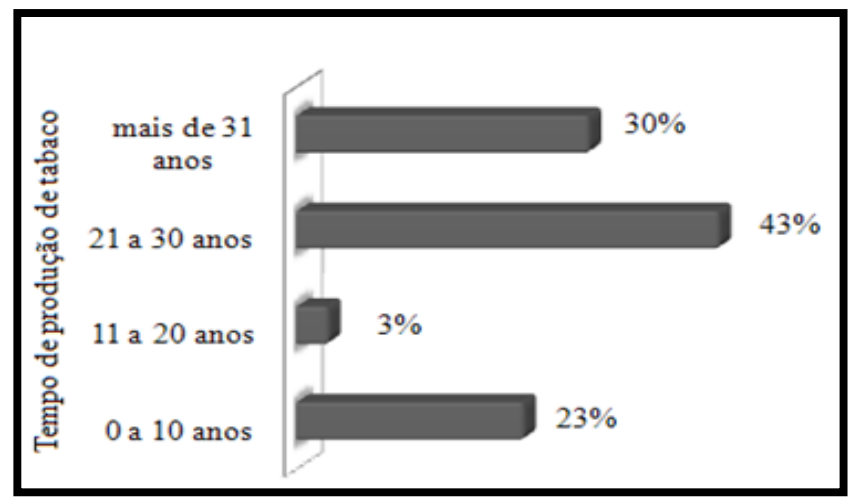

Fonte: Elaborada pela autora a partir das informações recolhidas pelos fumicultores da Linha João Alves, município de Santa Cruz do Sul, RS (2009).

Quanto à condição de posse da terra, a totalidade dos agricultores (100\%) declarou serem proprietários das terras que ocupam. O tamanho total das propriedades predominou entre 6 e 11 ha (63\%), sendo que $30 \%$ destas apresentam tamanho superior a 12 ha.

Figura 6. Tamanho total da propriedade rural na Linha João Alves, município de Santa Cruz do Sul, RS

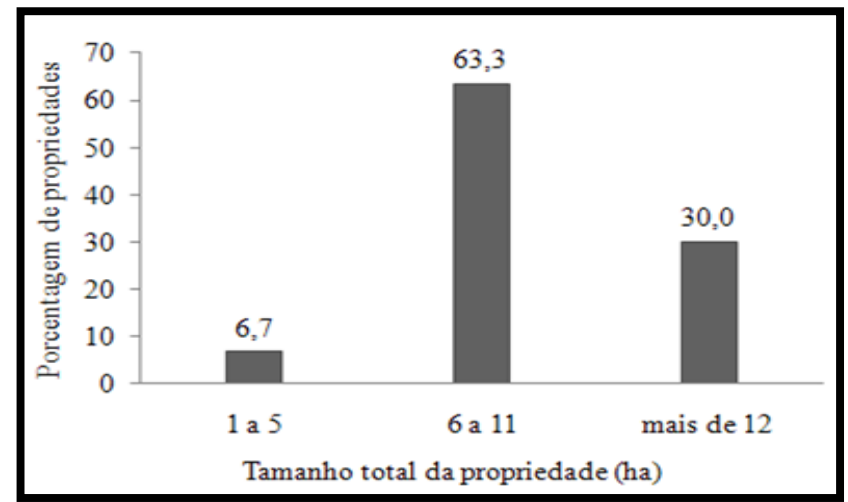

Fonte: Elaborada pela autora a partir das informações recolhidas pelos fumicultores da Linha João Alves, município de Santa Cruz do Sul, RS (2009).

No entanto, a área destinada à fumicultura não é superior a 6 ha, ocorrendo predomínio de lavouras de tabaco de 2 e 4 ha (Figura 7). O restante da área da propriedade é destinado ao cultivo de subsistência, sendo que todos os agricultores entrevistados declararam cultivarem outros produtos além do fumo (ex.: milho, feijão, mandioca, batata etc.), vendendo o excedente. 
Figura 7. Tamanho da lavoura de fumo na Linha João Alves, município de Santa Cruz do Sul, RS

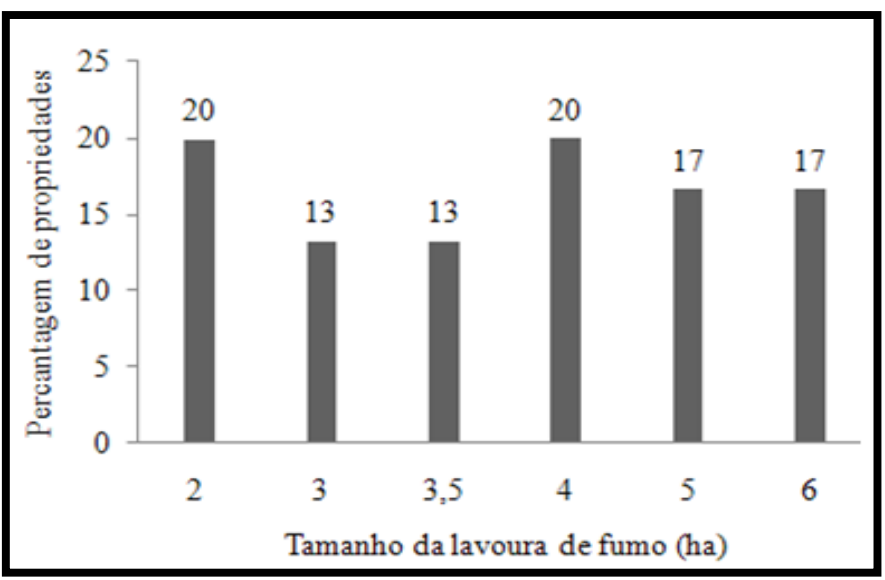

Fonte: Elaborada pela autora a partir das informações recolhidas pelos fumicultores da Linha João Alves, município de Santa Cruz do Sul, RS (2009).

Portanto, os fumicultores da Linha João Alves caracterizam-se por serem minifundiários, ou seja, pequenos produtores rurais, sendo a área média destinada à fumicultura de 3,9 ha. Alguns produtores justificaram essa pequena área em relação ao tamanho total da propriedade devido à existência de áreas impróprias para o cultivo de tabacos (ex.: áreas muito úmidas, de alta declividade etc.), além de necessitarem de terras também para determinadas culturas de subsistência.

Referindo-se aos produtores de tabaco do Sul do Brasil, SINDITABACO (2009a, p.8) também descreveu que esta tem como base as pequenas propriedades, em média com 16,1 hectares, sendo que destes, apenas 15\% (2,4 ha) são dedicados à produção de tabaco. Apesar da pequena área utilizada, o cultivo representa $70 \%$ da renda familiar dos agricultores. Justifica que a utilização de $15 \%$ da área da propriedade se deve ao grande volume de mão-de-obra exigido pela cultura.

Todos os fumicultores acham impossível a produção da cultura sem fazerem uso de agrotóxicos, sendo que quase a totalidade deles (93\%) afirmou a impossibilidade da produção. Uma minoria descreveu não haver possibilidade devido à grande queda da produção, enquanto outros devido ao fato da maior exigência de mão-de-obra (Figura 8).
Figura 8. Percepção quanto ao uso dos agrotóxicos entre os produtores de fumo na Linha João Alves, município de Santa Cruz do Sul, RS

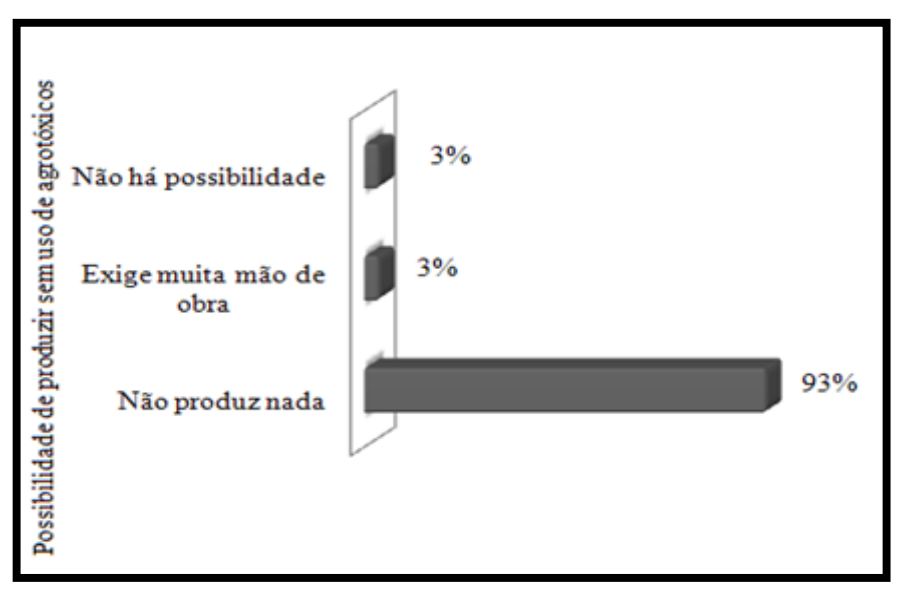

Fonte: Elaborada pela autora a partir das informações recolhidas pelos fumicultores da Linha João Alves, município de Santa Cruz do Sul, RS (2009).

Estão em desenvolvimento projetos no setor fumageiro para a produção de fumo sem adição de agroquímicos. Atualmente, não há demanda por esse produto, no entanto, quando o mercado o exigir, a indústria precisará estar pronta para abastecê-la. Os experimentos realizados até o momento alcançaram boa produtividade, mas a qualidade do produto ainda é inferior à média regional (NEUMANN, 2001, p. 99).

Em Linha João Alves, distrito do município de Santa Cruz do Sul, quando questionados sobre a indicação dos agrotóxicos a serem aplicados na lavoura do fumo, a maioria dos agricultores entrevistados citou serem orientados por técnicos de empresas fumageiras (22\%), sendo que alguns reconhecem que estes são orientados por Engenheiros Agrônomos. 
Figura 9. Indicação dos agrotóxicos na Linha João Alves, município de Santa Cruz do Sul, RS

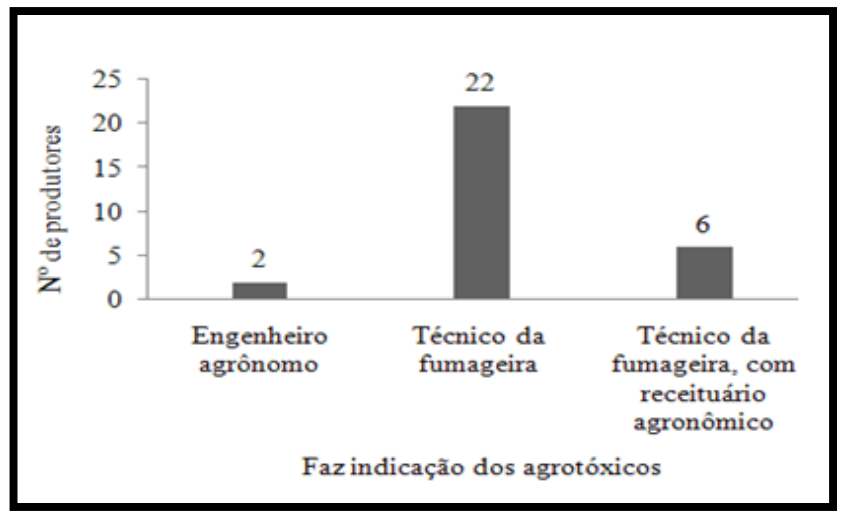

Fonte: Elaborada pela autora a partir das informações recolhidas pelos fumicultores da Linha João Alves, município de Santa Cruz do Sul, RS (2009).

Todos os agricultores adquirem os agrotóxicos das empresas fumageiras, sendo que adicionalmente alguns (43\%) ainda 0 adquirem de lojas especializadas, apesar de algumas empresas fumageiras não orientarem a compra de agrotóxico além da sua indicação.

Figura 10. Aquisição dos agrotóxicos utilizados na lavoura de fumo na Linha João Alves, município de Santa Cruz do Sul, RS

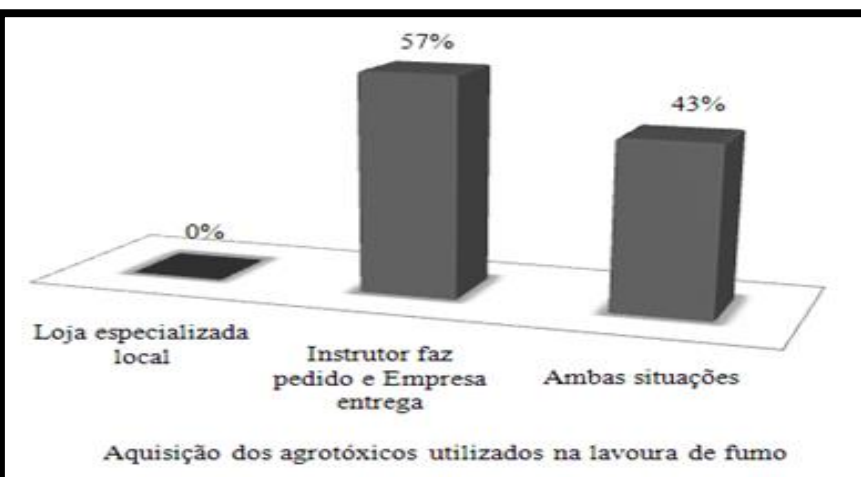

Fonte: Elaborada pela autora a partir das informações recolhidas pelos fumicultores da Linha João Alves, município de Santa Cruz do Sul, RS (2009).

O tipo de cultivo que não segue o que as empresas recomendam, baseando-se na utilização de insumos da propriedade e com redução de uso de pesticidas, é conhecido como cultivo alternativo. Há produtores que produziram fumo quase que totalmente sem pesticidas (com exceção ao antibrotante, para o qual não tem alternativa eficiente) e sem adubação química solúvel. Estas práticas diferem do cultivo convencional principalmente pela adoção dos seguintes manejos: queima de restos vegetais para a desinfestação das sementeiras; uso de resíduos de animais para a fertilização; cobertura do canteiro com uma camada de serragem; uso de inseticidas naturais como o extrato de fumo para afugentar insetos; uso de barreiras como casca de arroz, cinzas, serragem entre as sementeiras em substituição aos moluscicidas tradicionais (HERMES, 2002, p.41-42).

Quanto aos agrotóxicos utilizados na Linha João Alves, ocorreu predomínio do Primeplus $\AA^{\circ}$, sendo que o mesmo foi citado por 21 (70\%) dos agricultores, seguido pelo Orthene $\AA^{\circledR}$ (citado por $53 \%$ dos agricultores), Confidor $\AA$, Gamit®, Roundup $\AA$ (cada um deles citado por $30 \%$ dos agricultores), Actara ${ }^{\circledR}$ (citado por $20 \%$ dos agricultores), Ridomil $\circledast$ (citado por $17 \%$ dos agricultores) e Rovral ${ }^{\circledR}$ (citado por $10 \%$ dos agricultores). Alguns entrevistados $(17 \%)$ declararam serem muitos os agrotóxicos utilizados na lavoura de fumo, porém não souberam citar seus nomes (Figura 11).

Figura 11. Número de citações dos agrotóxicos utilizados na lavoura do fumo na Linha João Alves, município de Santa Cruz do Sul, RS (cada um dos 30 agricultores citou mais de um produto)

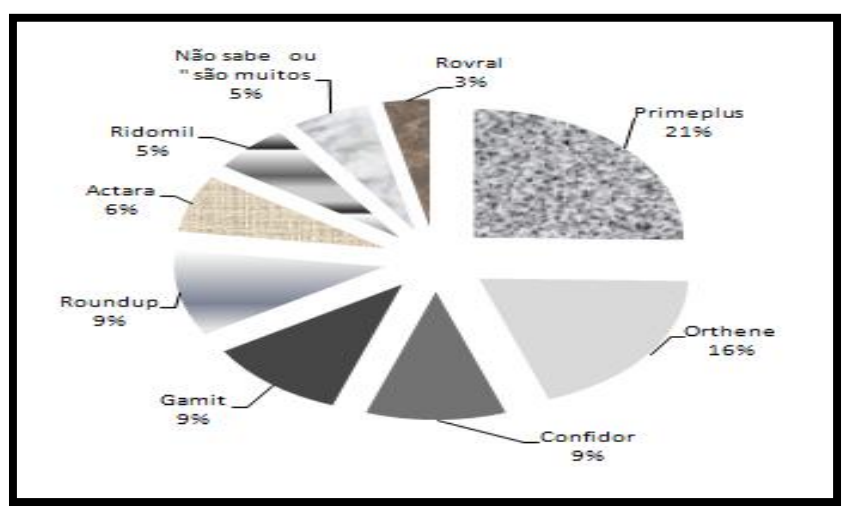

Fonte: Elaborada pela autora a partir das informações recolhidas pelos fumicultores da Linha João Alves, município de Santa Cruz do Sul, RS (2009).

Observa-se que a maioria dos agrotóxicos utilizados pelos produtores (indicados pelos técnicos das fumageiras) são pouco tóxicos. Nessa classificação incluem-se os agrotóxicos mais citados (Primeplus $\AA$, Orthene $\AA$, Confidor $\AA$ ), sendo este um ponto positivo. No entanto, um deles (Gamit®) é 
classificado como altamente tóxico, e outro (Actara®), como medianamente tóxico (Tabela 1 ).

Tabela 1. Uso e características dos principais agrotóxicos utilizados pelos produtores de tabaco na Linha João Alves, município de Santa Cruz do Sul, RS.

\begin{tabular}{|c|c|c|c|c|c|}
\hline Agrotóxico & $\begin{array}{l}\text { Etapa de } \\
\text { produção }\end{array}$ & Modo de ação & $\begin{array}{l}\text { Finalidade do uso } \\
\text { (Controle de) }\end{array}$ & Grupo químico & $\begin{array}{l}\text { Toxicologia } \\
\text { (classe } \\
\text { toxicológica) }\end{array}$ \\
\hline Primeplus & Lavoura & $\begin{array}{l}\text { Regulador de } \\
\text { crescimento }\end{array}$ & $\begin{array}{l}\text { Brotos situados nas } \\
\text { axilas das folhas da } \\
\text { planta }\end{array}$ & $\begin{array}{c}\text { Antibrotante } \\
\text { dinitroanilinas }\end{array}$ & $\begin{array}{l}\text { Pouco tóxico } \\
\text { (IV) }\end{array}$ \\
\hline Orthene & $\begin{array}{c}\text { Sementeira } \\
\text { e } \\
\text { lavoura }\end{array}$ & Sistêmico & $\begin{array}{l}\text { Pulgão; tripes do fumo; } \\
\text { percevejo frade; lagarta } \\
\text { rosca; pulga do fumo, } \\
\text { broca do fumo; lagarta }\end{array}$ & $\begin{array}{c}\text { Inseticida e } \\
\text { acaricida } \\
\text { organofosforado }\end{array}$ & $\begin{array}{l}\text { Pouco tóxico } \\
\text { (IV) }\end{array}$ \\
\hline Confidor & $\begin{array}{c}\text { Sementeira } \\
\text { e } \\
\text { lavoura }\end{array}$ & $\begin{array}{l}\text { Sistêmico, } \\
\text { contato e } \\
\text { ingestão }\end{array}$ & Broca do fumo; pulgão & $\begin{array}{c}\text { Inseticida } \\
\text { nitroguanidinas }\end{array}$ & $\begin{array}{l}\text { Pouco tóxico } \\
\text { (IV) }\end{array}$ \\
\hline Gamit & Lavoura & Herbicida & $\begin{array}{l}\text { Diversos inços em pré- } \\
\text { emergência }\end{array}$ & $\begin{array}{c}\text { Herbicida } \\
\text { isoxazolidinonas }\end{array}$ & $\begin{array}{l}\text { Altamente tóxico } \\
\text { (II) }\end{array}$ \\
\hline Roundup & Lavoura & $\begin{array}{l}\text { Herbicida } \\
\text { sistêmico não } \\
\text { seletivo }\end{array}$ & $\begin{array}{c}\text { Dessecar a massa } \\
\text { verde em pré plantio da } \\
\text { cultura }\end{array}$ & $\begin{array}{c}\text { Herbicida derivado } \\
\text { da glicina }\end{array}$ & $\begin{array}{l}\text { Pouco tóxico } \\
\text { (IV) }\end{array}$ \\
\hline Actara & $\begin{array}{c}\text { Sementeira } \\
\text { e } \\
\text { lavoura }\end{array}$ & Sistêmico & Pulgão; pulga do fumo & $\begin{array}{c}\text { Inseticida } \\
\text { neonicotinóides }\end{array}$ & $\begin{array}{l}\text { Medianamente } \\
\text { tóxico } \\
\text { (III) }\end{array}$ \\
\hline Ridomil & Lavoura & Sistêmico & Amarelão do fumo & Fungicida alaninatos & $\begin{array}{l}\text { Pouco tóxico } \\
\text { (IV) }\end{array}$ \\
\hline Rovral & Sementeira & Sistêmico & $\begin{array}{c}\text { Mela ou tombamento; } \\
\text { esclerotinia }\end{array}$ & $\begin{array}{c}\text { Fungicida } \\
\text { hidantoinas }\end{array}$ & $\begin{array}{l}\text { Pouco tóxico } \\
\text { (IV) }\end{array}$ \\
\hline
\end{tabular}

Fonte: Elaborada pela autora (2009).

Adaptado: A partir de Lima (2006, p. 202; 212-213).

Conforme Lima (2006, p.220), duas publicações no jornal Gazeta do Sul (23/09/97, p.9 e 14/11/97, p.12) denunciaram o efeito nocivo gerado pelo Gamit sobre plantas e animais em propriedades agrícolas no município de Venâncio Aires, RS, descrevendo que os efeitos do produto podem ser percebidos em outras plantações (milho, girassol, plantas ornamentais etc.) até 90 dias depois da sua aplicação na lavoura de fumo.

Quando questionados sobre o destino das embalagens vazias de agrotóxicos, a totalidade dos agricultores entrevistados respondeu que os mesmos estão sendo recolhidos nos últimos anos. Declararam que são orientados a fazerem a tríplice lavagem e posteriormente armazenar as embalagens vazias em sacos até serem recolhidos, ou então serem entregues no Sindicato dos Trabalhadores Rurais, em qualquer época. O recolhimento de embalagens vazias ocorre uma vez ao ano, e os agricultores da Linha João Alves são previamente avisados pelos técnicos das fumageiras sobre a data e local de coleta. No caso específico dessa localidade, o ponto de coleta é no Pavilhão da Comunidade Católica, sendo que no ano de 2009 foi realizada no dia 09 de fevereiro, às 7:30 horas.

A iniciativa de recolhimento das embalagens vazias de agrotóxicos ocorreu devido à promulgação da Lei n. 9 9.974, de 06 de junho de 2000, que disciplina a destinação final de embalagens vazias de agrotóxicos e distribui responsabilidades para o agricultor, comerciante, fabricante e ao poder público. Outra lei na qual o agricultor pode ser enquadrado e penalizado, caso não atenda às suas exigências, é a Lei dos Crimes Ambientais, Lei no. 9.605, de 13 de fevereiro de 1998, que dispõe sobre sanções penais e administrativas derivadas de condutas e atividades lesivas ao meio ambiente (CREA, 2007, p.18-20). Observa-se, portanto, que os fumicultores da Linha João Alves estão atendendo as referidas Leis.

Analisando o destino das embalagens vazias dos venenos realizado entre 146 produtores de tabaco na bacia hidrográfica do Rio Pardinho, em Santa Cruz do Sul, Etges (2006, p.237) descreveu 
que $16,4 \%$ desses o deixavam no campo, $14,4 \%$ os enterram, $15,8 \%$ os queimavam, $3,4 \%$ enviavam ao depósito municipal, $11,6 \%$ os colocavam em depósito próprio de lixo tóxico e 38,4\% davam outros destinos, tal como ensacar e colocar no galpão. Portanto, observa-se por este estudo que houve uma progressão do recolhimento das embalagens vazias de agrotóxicos quando comparado a estudos anteriores.

Os agricultores entrevistados nesta pesquisa, no entanto, não souberam explicar quem faz a coleta. A maioria apenas citou ser "um caminhão", enquanto outros arriscaram citar que é a Prefeitura e/ou empresas fumageiras.

Conforme SINDITABACO (2009b), o recebimento das embalagens segue um cronograma previamente estabelecido e amplamente divulgado pelos veículos de comunicação, pelos orientadores agrícolas das empresas fumageiras, inclusive em seu site (www.sinditabaco.com.br/). Em data, horário e local determinado, uma equipe especializada da Agrovete Centro de Serviços, de Santa Cruz do Sul, empresa contratada para a operacionalização do Programa, recolhe em caminhões as embalagens, após tríplice lavagem, mediante recibos.

Quanto à opinião dos agricultores sobre o melhor destino para as embalagens de agrotóxicos utilizados por eles nas lavouras, todos concordaram com o recolhimento. Antes da implantação do Programa de Recolhimento, os agricultores não sabiam o que fazer com as embalagens vazias, sendo muitas enviadas para aterro, "jogadas nos matos" ou queimadas, sendo que no último caso, gerava odor desagradável.

Quanto a problemas devido ao uso de agrotóxicos, a maioria dos entrevistados (90\%) descreveu não terem tido problemas. No entanto, obtiveram-se relatos de alguns ex-agricultores que deixaram de cultivar a referida cultura devido a problemas de saúde provocada pelos agrotóxicos. Devido a isso, passaram a produzir verduras. Os $10 \%$ que declararam terem tido problemas, citaram tontura e dor de cabeça.
Figura 12. Relatos de produtores de fumo quanto a problemas do uso de agrotóxicos na Linha João Alves, município de Santa Cruz do Sul, RS

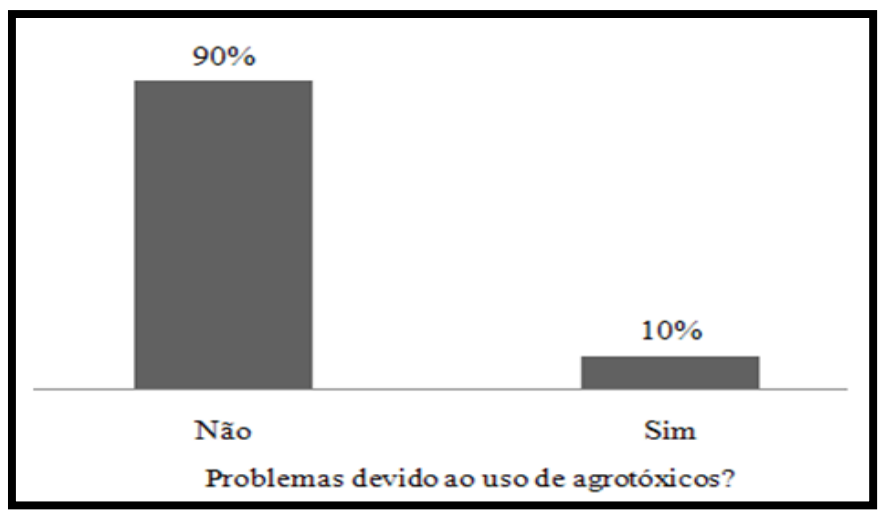

Fonte: Elaborada pela autora a partir das informações recolhidas pelos fumicultores da Linha João Alves, município de Santa Cruz do Sul, RS (2009).

Junto aos agrotóxicos, os fumicultores também recebem seus Equipamentos de Proteção Individual (EPI's) através do pacote tecnológico das empresas fumageiras. Declararam usar constantemente botas, luvas, chapéu e uniforme (calça e camisa), porém raramente usam máscara de proteção, alegando que a mesma "sufoca". Portanto, o predomínio do uso parcial de EPI's (73\%) refere-se à falta de uso da máscara de proteção (Figura 13).

Figura 13. Uso de EPI's na Linha João Alves, município de Santa Cruz do Sul, RS

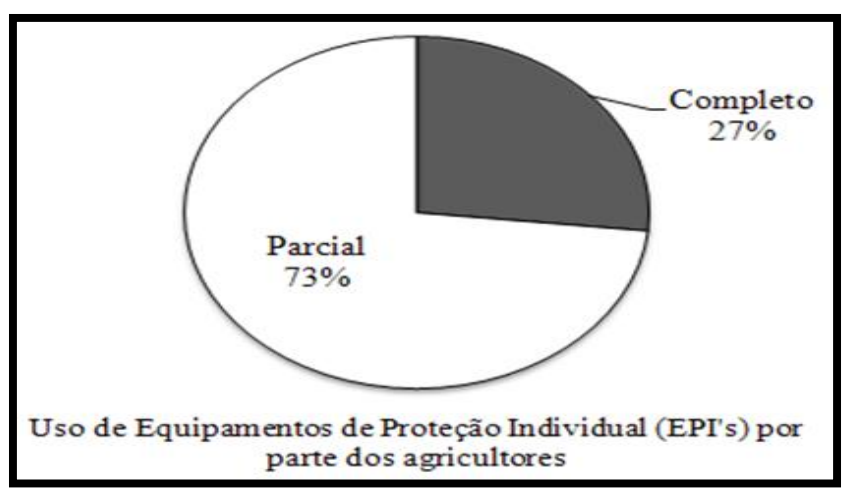

Fonte: Elaborada pela autora a partir das informações recolhidas pelos fumicultores da Linha João Alves, município de Santa Cruz do Sul, RS (2009).

Os EPI's, que tem como objetivo impedir o contato de agrotóxico no corpo humano, incluem bonés e chapéus com abas laterais, luvas, viseira protetora e máscara com filtro específico adequado ao produto utilizado. É obrigação do contratante de 
serviços rurais fornecer gratuitamente esses acessórios ao empregado (GONÇALVES, 2004, p.4).

De maneira semelhante a este estudo, pesquisa realizada na bacia hidrográfica do Rio Pardinho constatou que a maioria dos produtores de tabaco usam apenas botas e chapéus como forma de proteção. Os agricultores justificam que os meses de trabalho mais extensivo na lavoura do fumo são também os mais quentes do ano, o que inviabilizaria o uso dos EPl's. Desta forma, muitos aplicam os venenos totalmente desprovidos das vestimentas especiais (ETGES, 2006, p.235-236).

Quando questionados sobre as consequências para a saúde das pessoas e ao meio ambiente quando o descarte das embalagens de agrotóxicos não é feito corretamente, a opinião dos agricultores comprovou que eles têm consciência dos danos trazidos pelo descarte indevido destas embalagens. Algumas citações foram: "danos ao meio ambiente"; "contaminação dos rios, dos solos"; "muitas doenças atuais vêm do veneno utilizado antigamente" e "existem agora muitos mosquitos, devido à morte dos peixes pelos agrotóxicos, que é seu predador". Importante destacar que durante o período de entrevistas observou-se lenha de eucalipto nas proximidades das estufas de secagem de fumo, o que comprova, pelo menos em parte, que os agricultores não estão utilizando lenha proveniente de matas nativas.

\section{Considerações finais}

A atividade fumageira na Linha João Alves, município de Santa Cruz do Sul, RS, caracteriza-se por ser tipicamente familiar, sendo a maior parte da renda proveniente de um único produto (fumo), embora diversifiquem a produção para garantir a subsistência, além da exploração ser feita em pequenas áreas (tamanho médio de 3,9 ha).

Os fumicultores consideraram indispensável o uso de agrotóxicos na produção, sendo indicados e recebidos das empresas fumageiras.

Dentre os principais agrotóxicos citados estão o Primeplus, Orthene, Confidor, Gamit, Roundup,
Actara e o Rovral, sendo a maioria deles pouco tóxicos. Todas as embalagens vazias de agrotóxicos estão sendo recolhidas, conforme exigido pela Lei $n^{\circ}$ 9.974, de 06 de junho de 2000.

Todos os agricultores concordaram com o sistema de recolhimento de embalagens vazias de agrotóxicos, assim como eles também demonstraram haver conhecimento dos problemas ambientais e de saúde proporcionado pelo descarte indevido das embalagens.

Uma vez que o impacto dos pesticidas no meio ambiente e na saúde depende de muitos fatores, tais como composição química, persistência, mobilidade, dose aplicada e frequência do uso, torna-se difícil fazer uma estimativa aprofundada dos seus malefícios quando não empregadas avaliações laboratoriais em cada caso.

\section{Referências}

BONATO, A. A. A fumicultura no Brasil e a convenção-quadro para controle do tabaco. Curitiba: Departamento de Estudos Socioeconômicos Rurais, 2006. 53p.

BRASIL. Lei no. 9.974, de 06 de junho de 2000. Altera a Lei n. 7.802, de 11 de julho de 1989, que dispõe sobre a pesquisa, a experimentação, a produção, a embalagem e rotulagem, o transporte, 0 armazenamento, a comercialização, a propaganda comercial a utilização, a importação, a exportação, o destino final dos resíduos e embalagens, o registro, a classificação, o controle, a inspeção e a fiscalização de agrotóxicos, seus componentes e afins, e dá outras providencias. Diário Oficial [da] República Federativa do Brasil. Brasília, DF. DOFC, p 000001, 07 Jun. 2000. col.1.

BRASIL. Lei no. 7.802, de 11 de julho de 1989. Dispõe sobre as pesquisa, a experimentação, a produção, a embalagem e rotulagem, o transporte, o armazenamento, a comercialização, a propaganda comercial, a utilização, a importação, a exportação, o destino final dos resíduos e embalagens, o registro, a classificação, o controle, a inspeção e a fiscalização de agrotóxicos, seus componentes e afins, e dá outras providências. Diário Oficial [da] República Federativa do Brasil. Brasília, DF, 13 Jul. 1989.

BRASIL. Decreto no. 4074, de 04 de janeiro de 2002. Regulamenta a Lei no. 7.802, de 11 de julho de 1989, que dispõe sobre a pesquisa, experimentação, produção, embalagem, e rotulagem, transporte, armazenamento, 
comercialização, propaganda comercial, utilização, exportação, destino final dos resíduos, controle, inspeção e fiscalização e dá outras providencias. Diário Oficial [da] República Federativa do Brasil. Brasília, DF, DOFC, p 000001, 08 Jan. 2002. col.2.

BRASIL. Lei nํ. 9.605, de 12 de fevereiro de 1998. Lei de Crimes Ambientais, que Dispõe sobre as sanções penais e administrativas derivadas de condutas e atividades lesivas ao meio ambiente, e dá outras providências. Diário Oficial [da] República Federativa do Brasil. Brasília, DF. 30 Mar. 1998;

CREA - Conselho Regional de Engenharia, Arquitetura e Agronomia do Rio Grande do Sul. Embalagens de agrotóxicos: um desafio para a

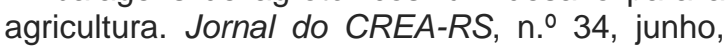
2007. 34 p.

ETGES, V. E. Aspectos sócio-econômico e possibilidade de diversificação entre os produtores de tabaco na Bacia Hidrográfica do Rio Pardinho/RS. In: ETGES, V.E.; FERREIRA, M.A.F (Orgs.). A produção de tabaco: impacto no ecossistema e na saúde humana na região de Santa Cruz do Sul/RS. Santa Cruz do Sul: EDUNISC, 2006. p 225-248.

ETGES, V. E; FERREIRA, M. A. F. A produção de tabaco: impacto no ecossistema e na saúde humana na região de Santa Cruz do Sul/RS. Santa Cruz do Sul: EDUNISC, 2006. 248 p.

GAZETA DO SUL. Jornal, Santa Cruz do Sul, RS. Panorama: Embalagens. Edição de 05 de outubro de 2009, p. 2. Ano 65, no. 216. 2009.

GONÇALVES, A. Cadeia produtiva do fumo: chega de servidão. Curitiba: Terra de Direitos Organização civil pelos direitos humanos, 2004, $12 \mathrm{p}$.

HERMES, Nadir. Estudo da incidência de resíduos de pesticidas nos alimentos produzidos nas áreas de plantio de tabaco na Bacia do Rio Pardinho, RS, Brasil. 2002. 133 f. Dissertação (Programa de Pós-Graduação em Desenvolvimento Regional-Mestrado e Doutorado) - Universidade de Santa Cruz do Sul, Santa Cruz do Sul, 2002.

IBGE. Instituto Brasileiro de Geografia e Estatística. Censo demográfico 2007. Disponível em <ibge.gov.br/cidadesat/topwindow.htm?1>. Acesso em 04 Mai. 2008.

LIMA, R. G. de. Desenvolvimento técnico-produtivo da lavoura de tabaco na Bacia Hidrográfica do Rio Pardinho/RS. In: ETGES, V.E.; FERREIRA, M.A.F (Orgs.). A produção de tabaco: impacto no ecossistema e na saúde humana na região de Santa Cruz do Sul/RS. Santa Cruz do Sul: EDUNISC, 2006. p 198-224.
MACHADO, D. Santa Cruz do Sul: um destino mais correto para as embalagens de agrotóxicos. Página Rural: notícia, 31 de julho de 2007. Disponível em: $<$ www.paginarural.com.br/noticias detalhes.php ?id=73507>. Acesso em 04 mai. 2008.

NEUMANN, R. I. (Editor). Anuário Brasileiro do Fumo. Santa Cruz do Sul: Gazeta Grupo de Comunicações, 2001. 128 p.

OLIVEIRA, M. L. F. de; SILVA, A. A.; BALLANI, T. S. L.; BELLASALMA, A. C. M. Sistema de notificação de intoxicações: desafios e dilemas. In: É veneno ou remédio: Agrotóxicos, saúde e ambiente. PERES, F.; MOREIRA, J. C. (orgs). Rio de Janeiro: FIOCRUZ, 2003. p. 303-315.

SINDIFUMO - Sindicato da Indústria do Fumo. Santa Cruz do Sul: Sindifumo, 2008. Disponível em $<$ http://www.sindifumo.com.br $>$. Acesso em 04 mai. 2008.

SINDITABACO - Sindicato da Indústria do Tabaco. Santa Cruz do Sul: Sinditabaco, 2009b. Disponível em <http://www.sinditabaco.com.br>. Acesso em 11 jul. 2009.

SINDITABACO - Sindicato da Indústria do Tabaco. A cultura do tabaco no Sul do Brasil 2009. Santa Cruz do Sul: Sinditabaco, 2009a, 20p. 
Apêndice 1. INSTRUMENTOS DE PESQUISA

EMBALAGENS VAZIAS DE AGROTÓXICOS: AVALIAÇÃO DOS FUMICULTORES DA LINHA JOÃO ALVES, MUNICÍPIO DE SANTA CRUZ DO SUL, RS

\section{QUESTIONÁRIO}

1- Identificação do Produtor / chefe da família:

( ) Masculino ( ) Feminino

2- Idade do produtor / chefe da família:

( ) até 20 anos ( ) 21 a 40 anos ( ) 41 a 60 anos

( ) maior de 60 anos

3- Nível de Escolaridade do chefe da família:

( ) Nenhuma ( ) primário incompleto ( ) primário completo ( ) Ensino fundamental incompleto ( ) Ensino fundamental completo ( ) Ensino médio completo ( ) Superior

\section{4- Condição de posse da terra:}

( ) proprietário ( ) arrendatário ( ) rendeiro-parceiro ( ) outros

5-Tamanho da propriedade rural de La. João Alves.

( ) menos de 1 ha ( ) de 1 a 5 ha ( ) de 6 a 11 ha

( ) mais de 12 ha.

Quantos hectares são utilizados para a plantação do tabaco.

6- Tempo que produz tabaco:
( ) 0 a 10 anos
( ) 11 a 20 anos
( ) 21 a 30 anos
( ) mais de 31 anos

7- Possibilidade do produtor em produzir tabaco sem agrotóxicos:

( ) não produz nada ( ) exige muita mão de obra ( ) falta conhecimento

( ) não há possibilidade.

Porque?

8- Quem indica os agrotóxicos a serem utilizados no tabaco:

( ) proprietário ( ) o vendedor da loja ( ) engenheiro agrônomo ( ) técnico da fumageira
9- Onde compra os agrotóxicos e outros insumos utilizados na lavoura do tabaco:

( ) loja especializada, comércio local ( ) o instrutor faz o pedido e a Empresa faz a entrega na propriedade ( ) ambas as situações

10- Quais os principais agrotóxicos utilizados na lavoura do tabaco?

11- Pratica outra cultura além do tabaco:

( ) sim $\quad$ )não

Quais:

12- Uso de Equipamentos de Proteção Individual (EPI):

( ) usa completo ( ) usa parcial ( ) não usa ( ) só usa para alguns produtos

13-Tiveram problemas (saúde ou meio ambiente) devido ao uso de agrotóxicos ou descarte indevido das embalagens?

( ) não ( ) sim.

Quais?.

14- Qual é o destino das embalagens vazias na propriedade:

( ) recolhida. Por quem?

( ) queima ( ) enterra ( ) joga fora ( ) outros

15- Em sua opinião, qual seria o destino correto para as embalagens de agrotóxicos utilizados na lavoura do

tabaco?

16- Em sua opinião, quais são as consequências para a saúde das pessoas e do meio ambiente quando o descarte das embalagens não é feito corretamente? 